\title{
Real-world study of afatinib in first-line or re-challenge settings for patients with EGFR mutant non-small cell lung cancer
}

\author{
Hisashi Tanaka ${ }^{1}$ (1) $\cdot$ Kageaki Taima $^{1} \cdot$ Masamichi Itoga ${ }^{1} \cdot$ Yoshiko Ishioka $^{1} \cdot$ Keisuke Baba $^{1} \cdot$ Toshihiro Shiratori $^{1}$. \\ Hiroaki Sakamoto ${ }^{1} \cdot$ Junichiro Tsuchiya ${ }^{1} \cdot$ Hideyuki Nakagawa $^{2} \cdot$ Yukihiro Hasegawa $^{3} \cdot$ Hideo Yasugahira $^{4}$. \\ Koichi Okudera ${ }^{5}$. Shingo Takanashi ${ }^{6}$. Sadatomo Tasaka ${ }^{1}$
}

Received: 25 February 2019 / Accepted: 26 April 2019 / Published online: 14 May 2019

(c) The Author(s) 2019

\begin{abstract}
Afatinib, a second-generation epidermal growth factor receptor (EGFR) - tyrosine kinase inhibitor (TKI) for mutant nonsmall cell lung cancer (NSCLC), was approved in Japan in 2014. This study evaluated clinical outcomes of afatinib in realworld practice. Medical records of patients who received afatinib for advanced EGFR-mutant NSCLC were retrospectively reviewed. In total, 128 patients were analyzed. Seventy-six patients received afatinib as the first-line setting and 52 as the re-challenge setting (i.e., after failure of prior first-generation TKI). There was no difference in patient characteristics, such as age, sex, and PS, between the first-line and the re-challenge settings. In the first-line setting, the median progression-free survival (PFS) was 17.8 months (95\% confidence interval [CI] 13.7-21.5 months). The overall survival (OS) was 39.5 months (95\% CI 34.4- not reached). The response rate (RR) was $64.4 \%$. Subset analysis indicated that patients with dose reduction showed longer PFS than those without dose reduction (18.5 months versus 7.9 months $)(P=0.016)$. In the re-challenge setting, the median PFS was 8.0 months (95\% CI 4.9-9.5 months). The RR was $25 \%$. Most common adverse events leading to dose modification or treatment discontinuation included diarrhea, paronychia, and oral mucositis in both settings. Interstitial lung disease occurred in 5.4\% (7/128). In the real-world practice in Japan, afatinib showed comparable or better efficacy compared with that shown in previous clinical trials in both the first-line and the re-challenge settings.
\end{abstract}

Keywords Non-small cell lung cancer $\cdot$ Epidermal growth factor receptor mutation $\cdot$ Afatinib $\cdot$ Frist line $\cdot$ Re-challenge

$\begin{array}{ll}\text { Abbreviations } \\ \text { NSCLC } & \text { Non-small cell lung cancer } \\ \text { EGFR } & \text { Epidermal growth factor receptor } \\ \text { TKIs } & \text { Tyrosine kinase inhibitors } \\ \text { PFS } & \text { Progression-free survival } \\ \text { OS } & \text { Overall survival } \\ \text { IRB } & \text { Institutional review board } \\ \text { RECIST } & \text { Response Evaluation Criteria in Solid Tumors } \\ \text { AEs } & \text { Adverse events } \\ \text { PS } & \text { Performance status } \\ \text { NOS } & \text { Not otherwise specified } \\ \text { CR } & \text { Complete response } \\ \text { PR } & \text { Partial response }\end{array}$

Electronic supplementary material The online version of this article (https://doi.org/10.1007/s12032-019-1278-9) contains supplementary material, which is available to authorized users.

Hisashi Tanaka

xyghx335@gmail.com

Extended author information available on the last page of the article
SD Stable disease

CI Confidence interval

PD Progressive disease

ILD Interstitial lung disease

\section{Introduction}

Lung cancer is one of the most common malignancies in the world, with non-small cell lung cancer (NSCLC) accounting for $85 \%$ [1]. Currently, the most established target is the epidermal growth factor receptor (EGFR), a member of the ErbB kinase family of structurally related receptor tyrosine kinases. In human, the ErbB family consists of EGFR (HER1, ErbB1), HER2 (ErbB2), HER3 (ErbB3), and HER4 (ErbB4) [2]. The prevalence of EGFR mutation is 50\% in Asian patients with NSCLC [3].

NSCLC with EGFR mutations is recommended to treat with molecular target therapy with EGFR-tyrosine kinase inhibitors (TKIs) [4-8]. Recently, a phase III FLAURA trial 
revealed that osimertinib has better progression-free survival (PFS) than the first-generation EGFR-TKIs (gefitinib and elrotinib) [9]. Afatinib, a second-generation EGFR-TKI, irreversibly blocks signaling through not only EGFR but also HER2 and ErbB4 [10, 11]. In two pivotal phase III studies, afatinib showed better PFS than standard platinum-based chemotherapy $[8,12]$. In subgroup analysis of Lux-lung 3 and Lux-lung 6 trials, afatinib provided a better overall survival (OS) benefit than standard chemotherapy [12]. The OS benefit with afatinib could be associated with its potential advantages in targeting the entire ErbB family rather than EGFR alone. In addition, Lux-lung 7 study revealed that afatinib might offer improved PFS compared with gefitinib [13].

Preclinical data suggested that afatinib is more active than first-generation EGFR-TKIs in NSCLC that acquired resistance to gefitinib or erlotinib [14]. Lux-lung 1 study, which examined the efficacy of afatinib in a re-challenge setting, did not show significant improvement in the OS, although the EGFR mutation status of the study subjects was not shown [15]. The efficacy of re-challenge treatment with afatinib for patients with EGFR-mutated metastatic NSCLC previously responsive to first-generation TKIs has not been clear. Here, we report a real-world data of afatinib in firstline or re-challenge settings for Japanese patients with EGFR mutant NSCLC.

\section{Patients and methods}

\section{Study design}

This study was a multicenter retrospective study involving 5 institutions in Aomori, Japan. We reviewed medical records of all the patients who were treated with afatinib at the participating hospitals. In the first-line setting, chemonaïve patients were screened. In the re-challenge setting, patients who had disease progression or discontinuation due to toxicity for at least one of first-generation TKIs were included. Because, in Japan, osimertinib was approved for NSCLC patients with T790 M mutation in May 2016, we excluded the patients who were diagnosed as NSCLC with T790 M mutation after May 2016. The study was performed according to the protocol approved by the ethics committee of each participating hospital. Institutional Review Board of Hirosaki University approved this study (approval number: 2016-1108). Because this was a retrospective cohort study, informed consent was waived. Opt out was done on the web site of Hirosaki University.

\section{Evaluation and statistical analysis}

All analyses were performed using JMP 13 (SAS Institute, Cary, NC, USA). PFS and OS were estimated using the Kaplan-Meier method. PFS has been defined as the time from the date of treatment initiation to the date of disease progression, death, or the last contact. If either event was not observed, survival event was considered to be censored with the latest observation date. If post-treatment is started, survival event was considered to be censored with the date of initiation of the next line chemotherapy. OS was defined as the time from the treatment initiation to any death. Tumor responses were assessed using chest computed tomographic scan. Unidirectional measurements were adopted on the basis of the Response Evaluation Criteria in Solid Tumors (RECIST), version 1.1. The adverse events (AEs) were graded using National Cancer Institute Common Toxicity Criteria Version 4.0. Differences were assumed to be significant when a $P$ value of $<0.05$ was achieved.

\section{Results}

\section{Patient characteristics}

From October 2014 to January 2017, a total of 128 patients were screened from 5 participating institutions in Aomori, Japan. Seventy-six patients received afatinib in the firstline setting (the first-line group) and 52 in the re-challenge setting (the re-challenge group). Table 1 showed the characteristics of the eligible patients.

In the first-line group, the median age was 68 years (range, $42-88$ years), and 52 patients $(68.4 \%)$ were under 75 years. There were 52 female patients $(68.4 \%)$. The number of patients with a performance status (PS) $0-1$ was 67 $(88.1 \%)$. Only $3(3.9 \%)$ patients had poor PS (3-4). Seventy-four patients (97.4\%) had adenocarcinoma histology. Only one patient (1.3\%) had squamous cell carcinoma, and another patient (1.3\%) had NSCLC not otherwise specified (NOS). Nine patients (11.8\%) had stage IIIB, 45 (59.3\%) had stage IV, and 22 (28.9\%) had recurrent disease. The EGFR mutation status was as follows: exon 19 deletion/ exon $21 \mathrm{~L} 858 \mathrm{R} /$ exon $18 \mathrm{G} 719 \mathrm{X}$ in $46 / 28 / 2$, respectively.

In the re-challenge group, the median age was 65 years (range, 39-90 years), and 41 patients $(78.9 \%$ ) were female sex. Most patients $(88.4 \%$ ) had PS $0-1$. The EGFR mutation status was as follows: exon 19 deletion/exon 21 L858R/exon 18 G719X in 29/21/2, respectively. Gefitinib was used most frequently as the previous treatment. Thirty-eight patients $(73.1 \%$ ) received afatinib as the $3 \mathrm{rd}$ 
Table 1 Patient characteristics $(N=128)$

\begin{tabular}{|c|c|c|}
\hline Characteristic & $\begin{array}{l}\text { First line setting } \\
(N=76)\end{array}$ & $\begin{array}{l}\text { Re-challenge } \\
\text { setting } \\
(N=52)\end{array}$ \\
\hline \multicolumn{3}{|l|}{ Gender } \\
\hline Male & $24(31.6)$ & $11(21.1)$ \\
\hline Female & $52(68.4)$ & $41(78.9)$ \\
\hline Age (years), median (range) & $68(42-88)$ & $65(37-90)$ \\
\hline$<75$ & $52(68.4)$ & $38(73.1)$ \\
\hline $75 \geqq$ & $24(31.6)$ & $14(26.9)$ \\
\hline \multicolumn{3}{|l|}{ ECOG PS, $n(\%)$} \\
\hline $0-1$ & $67(88.1)$ & $46(88.4)$ \\
\hline 2 & $6(8.0)$ & $4(7.7)$ \\
\hline $3-4$ & $3(3.9)$ & $2(3.9)$ \\
\hline \multicolumn{3}{|l|}{ Clinical stage $n(\%)$} \\
\hline IIIB & $9(11.8)$ & - \\
\hline IV & $45(59.3)$ & - \\
\hline Recurrence & $22(28.9)$ & $52(100)$ \\
\hline \multicolumn{3}{|l|}{ Histological type, $n(\%)$} \\
\hline Adenocarcinoma & $74(97.4)$ & $51(98.0)$ \\
\hline Squamous & $1(1.3)$ & $1(2.0)$ \\
\hline NOS & $1(1.3)$ & 0 \\
\hline \multicolumn{3}{|l|}{ Smoking history, $n(\%)$} \\
\hline Never smoker & $56(73.7)$ & $45(86.5)$ \\
\hline Light smoker & $20(26.3)$ & $7(13.5)$ \\
\hline \multicolumn{3}{|l|}{ EGFR mutation, $n(\%)$} \\
\hline Exon 19 del & $46(50.7)$ & $29(55.8)$ \\
\hline Exon $21 \mathrm{~L} 858 \mathrm{R}$ & $28(46.7)$ & $21(40.4)$ \\
\hline Exon 18 G719 & $2(2.6)$ & $2(3.8)$ \\
\hline \multicolumn{3}{|l|}{ Treatment line, $n(\%)$} \\
\hline 1 & $76(100)$ & 0 \\
\hline 2 & 0 & $14(26.9)$ \\
\hline 3 & 0 & $20(38.5)$ \\
\hline More than 4 & 0 & $18(34.6)$ \\
\hline \multicolumn{3}{|l|}{ Previous treatment } \\
\hline Gefitinib & - & $37(73.1)$ \\
\hline Erlotinib & - & $9(15.4)$ \\
\hline Both & - & $6(11.5)$ \\
\hline
\end{tabular}

ECOG Eastern Cooperative Oncology Group, PS performance status, $E G F R$ epidermal growth factor receptor, NOS not otherwise specified

or later line treatment. On the other hand, 14 patients $(26.9 \%)$ were treated as the second line. In the second line setting, twelve (85.7\%) discontinued the prior EGFR-TKI treatment due to its toxicity.

\section{Efficacy}

- The response to afatinib treatment in the first-line setting is summarized in Table 2. One patient achieved complete response (CR) and 48 patients attained a partial response (PR). The ORR was $64.4 \%$. Sixteen patients (34.3\%) had
Table 2 Overall response to treatment

\begin{tabular}{lll}
\hline Response & \multicolumn{2}{l}{ Number of patients $(\%)$} \\
\cline { 2 - 3 } & $\begin{array}{l}\text { First-line setting } \\
(N=76)\end{array}$ & $\begin{array}{l}\text { Re-challenge } \\
\text { setting } \\
(N=52)\end{array}$ \\
\hline Complete response & $1(1.3)$ & $1(1.9)$ \\
Partial response & $48(63.1)$ & $12(23.1)$ \\
Stable disease & $16(34.3)$ & $29(55.9)$ \\
Progressive disease & $1(1.3)$ & $6(11.5)$ \\
Not evaluable & $10(7.6)$ & $4(7.6)$ \\
Response rate $(\%)$ & $64.4 \%$ & $25 \%$ \\
\hline
\end{tabular}

stable disease (SD). The median PFS was 17.8 months (95\% confidence interval [CI] 13.7-21.5) (Fig. 1a). The OS was 39.5 months (95\% CI 34.4- not reached) (Fig. 1b). We conducted additional subgroup analysis about relationship between patient characteristics and survival outcome. There was no difference in median PFS and OS according to age $(\leq 74$ or $75 \leq$ ) (Supplementary Fig. 1). The ORR was $74.9 \%$ in elderly group. One patient CR and 17 patients attained a PR. Fifty-eight patients (76.3\%) received reduced dose of afatinib due to adverse events. However, dose reduction did not affect its efficacy in terms of OS (39.5 months in the patients with dose reduction vs. not yet reached in those without, $P=0.37$ ). Moreover, the patients with dose reduction showed even longer PFS than those without (18.5 months and 7.9 months, respectively) $(P=0.018)$ (Fig. 1c). There was no difference in median PFS and OS between the patients with exon 19 deletion and those with exon 21 L858R mutation (Supplementary Fig. 2). There were two patients with minor mutation in the first-line setting. One patient had PR and the other had SD. The PFS was 7.8 months in these two patients.

In the re-challenge setting, 1 patient had CR and 12 attained PR. The RR was $25 \%$, and 29 patients $(55.9 \%)$ had SD (Table 2). The median PFS was 8.0 months (95\% CI 4.9-9.5) (Fig. 2). There was no difference in median PFS according to mutation status or prior TKI regimen. In second line setting, there were twelve $(85.7 \%)$ of 14 patients who discontinued the prior EGFR-TKI treatment due to its toxicity. We conducted additional analysis of ORR and PFS of 12 patients excluded. The ORR was $22 \%$, and the median PFS was 5.7 months (95\% CI 3.3-7.6) (Supplementary Fig. 3).

\section{T790 M status after first-line afatinib}

Forty-eight patients had progressive disease (PD) at the time of analysis, 28 patients underwent re-biopsy. Sixteen patients (57.1\%) were positive of T790 M after the first-line 

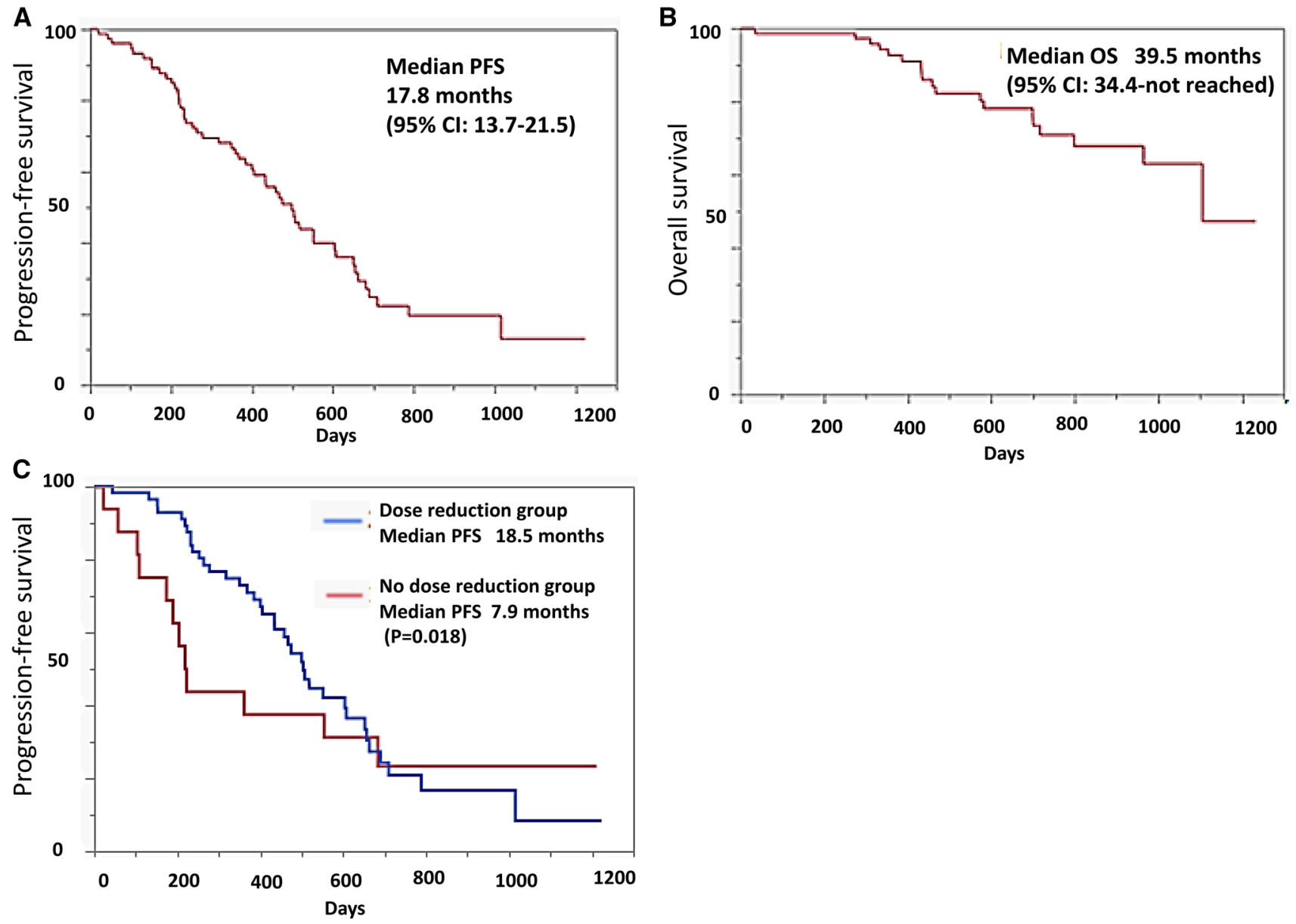

Fig. 1 Kaplan-Meier analysis of progression-free survival in the first-line setting. The median progression-free survival was 17.8 months (a). The overall survival was 39.5 months (b). The reduction group showed even longer PFS than the no reduction group (c)

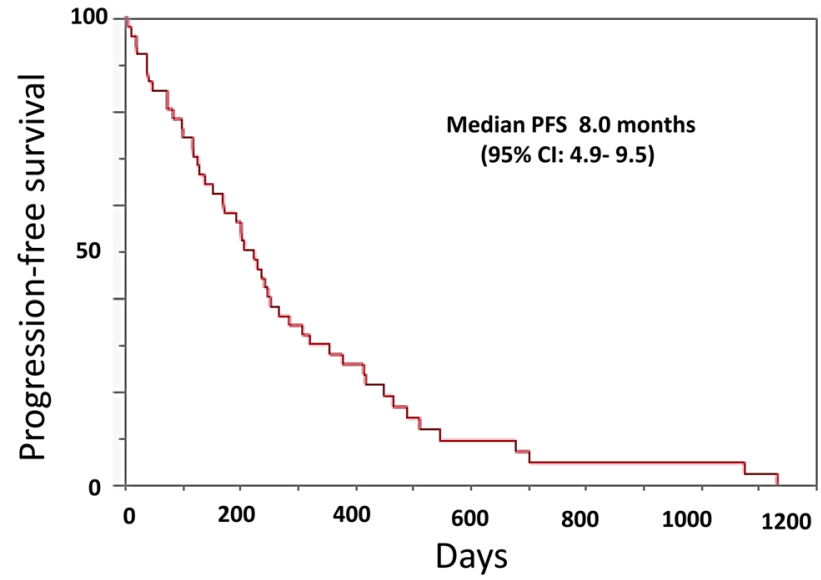

Fig. 2 Kaplan-Meier analysis of progression-free survival in the rechallenge setting. The median PFS was 8.0 months

afatinib treatment. The OS data of T790 M positive cases was 42.3 months (95\% CI 26.9-42.5) (Supplementary Fig. 4).

\section{Toxicity analysis}

The major toxicities in both settings are shown in Table 3 . Most of the patients who received afatinib needed dose reduction. The primary reasons for dose reduction included diarrhea, paronychia, and oral mucositis. Grade 3 or higher hematologic toxicities observed were anemia $(5.2 \%)$ in the first-line setting and neutropenia (3.8\%) and anemia (3.9\%) in the re-challenge setting. Grade 3 nonhematologic toxicities observed frequently included skin rush $(11.8 \%)$, anorexia (14.4\%), and diarrhea $(7.8 \%)$ in the first-line setting and, rush (4.3\%), anorexia (7.6\%), diarrhea (13.4\%) in the re-challenge setting. Grade 1 or 2 non-hematologic toxicities were fatigue, paronychia, oral mucositis, abnormal liver dysfunction and infection, which were generally mild and reversible. Interstitial lung disease (ILD) was observed in 7 patients (5.7\%). There was no grade 4 or 5 ILD in this study. 
Table 3 Toxicity in patients treated with afatinib

\begin{tabular}{lllllll}
\hline Afatinib & \multicolumn{2}{l}{ Frist-line setting $(N=76) n(\%)$} & \multicolumn{2}{l}{ Re-challenge setting $(N=52) n(\%)$} \\
\hline Grade (CTCAE) v4.0 & $1-2$ & 3 & 4 & $1-2$ & 3 & 4 \\
Neutropenia & $7(9.1)$ & 0 & 0 & $3(5.7)$ & $1(1.9)$ & $1(1.9)$ \\
Anemia & $18(23.6)$ & $4(5.2)$ & 0 & $14(27.4)$ & $2(3.9)$ & 0 \\
Thrombocytopenia & $2(2.6)$ & 0 & 0 & $1(1.9)$ & 0 & 0 \\
Anorexia & $17(22.3)$ & $11(14.4)$ & 0 & $7(13.4)$ & $4(7.6)$ & 0 \\
Fatigue & $17(22.3)$ & 0 & 0 & $9(17.2)$ & $1(1.9)$ & 0 \\
Diarrhea & $61(80.1)$ & $6(7.8)$ & 0 & $36(49.2)$ & $7(13.4)$ & 0 \\
Rash & $57(74.9)$ & $9(11.8)$ & 0 & $42(80.7)$ & $2(4.3)$ & 0 \\
Paronychia & $53(69.7)$ & $1(1.3)$ & 0 & $38(73.0)$ & 0 & 0 \\
Oral mucositis & $47(61.7)$ & $2(2.6)$ & 0 & $22(42.2)$ & 0 & 0 \\
Increased AST & $37(48.6)$ & $4(5.2)$ & 0 & $24(46.1)$ & $3(5.7)$ & 0 \\
Infection & $10(14.4)$ & $3(4.3)$ & 0 & $5(10.7)$ & $2(4.3)$ & 0 \\
Increased creatinin & $19(24.9)$ & $2(2.6)$ & 0 & $15(28.8)$ & 0 & 0 \\
ILD & $1(1.3)$ & $2(2.6)$ & 0 & $3(5.7)$ & $1(1.9)$ & 0 \\
\hline
\end{tabular}

CTCAE Common Terminology Criteria for Adverse Events, AST aspartate aminotransferase, ILD interstitial lung disease

\section{Discussion}

This is one of the largest real-world studies that evaluated the efficacy of afatinib for patients with advanced NSCLC harboring EGFR mutations in both the first-line and the re-challenge settings. In the first-line setting, we revealed afatinib provided PFS of 17.8 months and OS of 39.5 months, which were longer than the numbers shown in Lux-lung 3 (11.1 months and 33.3 months, respectively), Lux-lung 6 (11.0 months and 31.4 months, respectively), and Lux-lung 7 (11.0 months and 27.9 months, respectively) studies $[8,13,16]$. Recently, Liang and colleagues evaluated the real-world efficacy of afatinib in patients with EGFR mutations in Taiwan and reported that median PFS and OS were 12.8 and 36.7 months, respectively [17]. Although the OS was close to our data, the PFS was longer.

A third-generation EGFR-TKI, osimertinib, has recently been compared with gefitinib or erlotinib in the global phase III FLAURA trial [9]. The median PFS was 18.9 months in the osimertinib arm, although OS data are currently immature. However, second-generation EGFR-TKIs were not included in the comparator arm, which made it difficult to draw conclusions regarding potential benefits of osimertinib over afatinib or dacomitinib in the first-line setting. In our study, the PFS data were comparable to that of osmertinib shown in the FLAURA trial. Moreover, in an observational study, Hochmair and colleagues reported long OS outcome in patients with EGFR mutation-positive NSCLC receiving sequential afatinib and osimertinib, especially in those with exon 19 deletion (30.3 months [90\% CI 27.6-44.5]) or Asian (46.7 months [90\% CI 26.8-not reached]) [18]. They suggested that first-line afatinib followed by osimertinib in patients with NSCLC who acquire T790 M might be a feasible therapy.

In our study, which included elderly patients (31.6\%), there were no differences in median PFS and OS between younger patients and elderly. There have been a few reports that prospectively evaluated the efficacy and safety profile of afatinib in the elderly patients. Imai and colleagues recently reported the first study of afatinib (30 mg/day) for the elderly $(70 \leq)$ patients harboring sensitive EGFR mutations. The median PFS was 12.9 months [19]. Our data of the PFS in elderly were 15.4 months. Paz-Ares and colleagues reported that there was no difference in OS among patient subgroups and that similar median OS was seen at cutoffs of 60, 65, 70, and 75 years old [13, 20]. Moreover, we previously reported the phase I trial of afatinib for elderly patients $(75 \leq)$. Although dose reduction rate of afatinib was high, the response rate was as high as $73.3 \%$ and PFS was 22 months (95\% CI 13.1- not reached) [21].

The most frequent drug-related AEs in the current study were diarrhea, rash, paronychia, and oral mucositis, which were main reasons for the dose modification. However, the dose reduction did not affect the efficacy of afatinib. Preferably, the patients with dose reduction showed even longer PFS than those without dose reduction. In our study, interstitial lung disease was observed in 5.7\%, which was similar to the numbers in previous reports [21].

In the present study, two patients with G719X, one of minor mutations of EGFR gene, were included and their median PFS was 7.8 months, although the sample size was too small to discuss the efficacy of afatinib for NSCLC with minor mutations. EGFR mutations G719X and L861Q are found in approximately $3 \%$ and $2 \%$ in NSCLC with EGFR mutation, respectively [22]. In a retrospective study that 
included 16 patients with minor mutations, first-generation EGFR-TKIs provided the median PFS of 1.5 months and the RR of 25.0\% [23]. Yang and colleagues reported the efficacy of afatinib in 38 patients with advanced NSCLC harboring minor mutations. The RR was $71.1 \%$, and the median PFS and OS were 10.7 and 18.6 months, respectively [24]. These data suggest that, in NSCLC patients with minor mutations, afatinib may have greater efficacy than first-generation EGFR-TKIs.

In the re-challenge setting, the RR was $25 \%$, and 29 patients $(55.9 \%)$ had SD. The median PFS was 8.0 months (95\% CI 4.9-9.5). We summarized 4 prospective studies and 1 retrospective study that evaluated the efficacy of afatinib on NSCLC patients in whom prior EGFR-TKIs failed (Table 4). The Lux-lung 1 investigated the efficacy of afatinib in patients who had PD after first-generation EGFR-TKI, which showed improvement of a median PFS in those treated with afatinib without improvement in the OS. EGFR mutation status was not evaluated in the Luxlung 1 study [25]. Lux-lung 4 study was a phase II trial in Japan, which evaluated the efficacy of afatinib monotherapy as the in third- or fourth-line treatment in patients with NSCLC who had PD while receiving erlotinib and/or gefitinib treatment. The ORR was $8.2 \%$, which did not meet the primary endpoint, and the median PFS was 4.4 months [26]. In another prospective study, Lee and colleagues reported afatinib might offer improved PFS and ORR compared with erlotinib in Chinese patients [27]. Other studies also showed that afatinib provided approximately 4 months of PFS [28, 29]. Our study showed better PFS compared to these previous reports.

In our study, 14 patients $(26.9 \%)$ received afatinib as the second line treatment. Twelve patients $(85.7 \%)$ of them discontinued prior EGFR-TKI treatment due to toxicity, which might be one of the main reasons for their long PFS.

Chemotherapy has been a common option for the patients who had PD for EGFR-TKI. In the previous clinical trials, ORR ranged about $8.8-22.9 \%$ and median PFS was 2.9-4.5 months for patients who received chemotherapy [30, 31]. The hematologic adverse effects were more common in chemotherapy. Considering the efficacy and toxicity, afatinib could be a treatment choice as salvage therapy.

In our clinical practice, osimertinib has been used in the first-line treatment for EGFR mutant NSCLC. The efficacy data of the first- or second-generation EGFR-TKIs for patients with T790 M negative NSCLC who had PD after osimertinib is needed.

The present study has some limitations. First, because our study was retrospective, the schedule of image inspection of tumor was not determined, which might affect the PFS estimation. Second, efficacy measurements were not taken by central review but by each investigator. Finally, as we collected the data before approval of osimertinib in Japan, T790 M mutation was not examined. Since T790 M positive patients are currently treated with osimertinib, rechallenge data in patients with T790 M negative NSCLC will be required.

\section{Conclusions}

In conclusion, afatinib showed a manageable safety profile and comparable or better efficacy in real-world practice in both the first-line and the re-challenge settings compared with those described in previous reports. Dose reduction or age factor did not affect the efficacy of afatinib.
Table 4 Summary of previous trials

\begin{tabular}{lllll}
\hline Reference & Regimen & EGFR (+) & ORR & PFS (months) \\
\hline $\begin{array}{l}\text { LUX-Lung1 (25) } \\
(n=585)\end{array}$ & Afatinib vs Placebo & NE & $7 \%$ vs < $\%$ & 3.3 vs 11.1 \\
$\begin{array}{l}\text { prospective } \\
\text { LUX-Lung 4 (26) } \\
(n=62)\end{array}$ & Afatinib & $72.6 \%$ & $8.2 \%$ & 4.4 \\
$\begin{array}{l}\text { prospective } \\
\begin{array}{l}\text { Lee et al. (27) } \\
\text { prospective }\end{array}\end{array}$ & Afatinib vs. erlotinib & $100 \%$ & $20 \%$ vs $7.1 \%$ & 4.1 vs 3.3 \\
$\begin{array}{l}\text { Chang et al. (28) } \\
\begin{array}{l}\text { Retro } \\
(n=205)\end{array}\end{array}$ & Gefitinib Afatinib Erlotinib & $100 \%$ & $7.3 \%$ & 4.1 \\
$\begin{array}{l}\text { Schuler et al. (29) } \\
\text { prospective } \\
(n=325)\end{array}$ & Afatinib & $100 \%$ & NE & \\
\begin{tabular}{l} 
Present Study \\
\hline
\end{tabular} & Afatinib & $100 \%$ & $25 \%$ & 8.6 \\
\hline
\end{tabular}

$E G F R$ epidermal growth factor receptor, $O R R$ overall response rate, $P F S$ progression-free survival, $N E$ not evaluated 
Acknowledgements The authors are grateful to the patients and their family and medical staffs who contributed to this study.

Author contributions HT and KT prepared the manuscript and the literature search; HT and MI conducted statistical analysis; YI, KB, TS, HS and JT contribute to treated and observed patients in Hirosaki University; $\mathrm{HN}$ treated and observed patients in Hirosaki National Hospital; YH treated and observed patients in Aomori Prefectural Central Hospital; HY treated and observed patients in Hachinohe City Hospital; KO treated and observed patients in Hirosaki Central Hospital; ST and ST reviewed the manuscript. All authors read and approved the final manuscript.

Funding This research did not receive any specific grant from funding agencies in the public, commercial, or not-for-profit sectors.

\section{Compliance with ethical standards}

Conflict of interest All authors declared that they have no competing interests.

Ethical approval All procedures performed in studies involving human participants were in accordance with the ethical standards of the institutional and/or national research committee and with the 1964 Helsinki Declaration and its later amendments or comparable ethical standards. The study was approved by the institutional review boards of all participating institutions. (approval number: 2016-1108).

Informed consent Because this was a retrospective cohort study, informed consent was waived. Opt out was done on the web site of Hirosaki University.

Open Access This article is distributed under the terms of the Creative Commons Attribution 4.0 International License (http://creativeco mmons.org/licenses/by/4.0/), which permits unrestricted use, distribution, and reproduction in any medium, provided you give appropriate credit to the original author(s) and the source, provide a link to the Creative Commons license, and indicate if changes were made.

\section{References}

1. Siegel R, Naishadham D, Jemal A. Cancer statistics 2012. CA Cancer J Clin. 2012;62:10-29.

2. Roskoski R Jr. The ErbB/HER family of proteintyrosine kinases and cancer. Pharmacol Res. 2014;79:34-74.

3. Shi Y, Au JS, Thongprasert S, et al. A prospective, molecular epidemiology study of EGFR mutations in Asian patients with advanced non-small-cell lung cancer of adenocarcinoma histology (PIONEER). J Thorac Oncol. 2014;9:154-62.

4. Maemondo M, Inoue A, Kobayashi K, et al. Gefitinib or chemotherapy for non-small-cell lung cancer with mutated EGFR. N Engl J Med. 2010;362:2380-8.

5. Mitsudomi T, Morita S, Yatabe Y, et al. Gefitinib versus cisplatin plus docetaxel in patients with non-small-cell lung cancer harbouring mutations of the epidermal growth factor receptor (WJTOG3405): an open label, randomised phase 3 trial. Lancet Oncol. 2010;11:121-8.

6. Zhou C, Wu YL, Chen G, et al. Erlotinib versus chemotherapy as frst-line treatment for patients with advanced EGFR mutationpositive non-small-cell lung cancer (OPTIMAL, CTONG-0802): a multicentre, open-label, randomised, phase 3 study. Lancet Oncol. 2011;12:735-42.

7. Rosell R, Carcereny E, Gervais R, et al. Erlotinib versus standard chemotherapy as first-line treatment for European patients with advanced EGFR mutation-positive non-small-cell lung cancer (EURTAC): a multicentre, open-label, randomised phase 3 trial. Lancet Oncol. 2012;13:239-46.

8. Wu YL, Zhou C, Hu CP, et al. Afatinib versus cisplatin plus gemcitabine for first-line treatment of Asian patients with advanced non-small-cell lung cancer harbouring EGFR mutations (LUX-Lung 6): an open-label, randomised phase 3 trial. Lancet Oncol. 2014;15:213-22.

9. Soria JC, Ohe Y, Vansteenkiste J, et al. Osimertinib in untreated EGFR-mutated advanced non-small-cell lung cancer. N Engl J Med. 2018;378:113-25.

10. Hynes NE, Lane HA. ERBB receptors and cancer: the complexity of targeted inhibitors. Nat Rev Cancer. 2005;5:341-54.

11. Li D, Ambrogio L, Shimamura T, et al. BIBW2992, an irreversible EGFR/HER2 inhibitor highly effective in preclinical lung cancer models. Oncogene. 2008;27:4702-11.

12. Yang JC, Wu YL, Schuler M, et al. Afatinib versus cisplatinbased chemotherapy for EGFR mutation-positive lung adenocarcinoma (LUX-Lung 3 and LUX-Lung 6): analysis of overall survival data from two randomised, phase 3 trials. Lancet Oncol. 2015;16:141-51.

13. Paz-Ares L, Tan EH, O’Byrne K, et al. Afatinib versus gefitinib in patients with EGFR mutation-positive advanced non-smallcell lung cancer: overall survival data from the phase IIb LUXLung 7 trial. Ann Oncol. 2017;28:270-7.

14. Solca F, Dahl G, Zoephel A, et al. Target binding properties and cellular activity of afatinib (BIBW 2992), an irreversible ErbB family blocker. J Pharmacol Exp Ther. 2012;343:342-50.

15. Miller VA, Hirsh V, Cadranel J, et al. Afatinib versus placebo in patients with advanced, metastatic non-small-cell lung cancer after failure of erlotinib, gefitinib, or both, and one or two lines of chemotherapy (LUX-Lung 1 ): a phase $2 \mathrm{~b} / 3$ randomised trial. Lancet Oncol. 2012;13:528-38.

16. Sequist LV, Yang JC, Yamamoto N, et al. Phase III study of afatinib or cisplatin plus pemetrexed in patients with metastatic lung adenocarcinoma with EGFR mutations. J Clin Oncol. 2013;31:3327-34.

17. Liang SK, Lee MR, Liao WY, et al. Prognostic factors of afatinib as a first-line therapy for advanced EGFR mutationpositive lung adenocarcinoma: a real-world, large cohort study. Oncotarget. 2018;9:23749-60.

18. Hochmair MJ, Morabito A, Hao D, et al. Sequential treatment with afatinib and osimertinib in patients with EGFR mutationpositive non-small-cell lung cancer: an observational study. Future Oncol. 2018;14:2861-74.

19. Imai H, Kaira K, Suzuki K, et al. A phase II study of afatinib treatment for elderly patients with previously untreated advanced non-small-cell lung cancer harboring EGFR mutations. Lung Cancer. 2018;126:41-7.

20. Liu CY, Wang CL, Li SH, et al. The efficacy of $40 \mathrm{mg}$ versus dose de-escalation to less than $40 \mathrm{mg}$ of afatinib (Giotrif) as the first-line therapy for patients with primary lung adenocarcinoma harboring favorable epidermal growth factor mutations. Oncotarget. 2017;8:97602-12.

21. Tanaka H, Taima K, Tanaka Y, Itoga M, Ishioka Y, et al. A phase I study of afatinib for patients aged 75 or older with advanced non-small cell lung cancer harboring EGFR mutations. Med Oncol. 2018;35:34.

22. Murray S, Dahabreh IJ, Linardou H, et al. Somatic mutations of the tyrosine kinase domain of epidermal growth factor receptor and tyrosine kinase inhibitor response to TKIs in non-small 
cell lung cancer: an analytical database. J Thorac Oncol. 2008;3:832-9.

23. Watanabe S, Minegishi Y, Yoshizawa H, et al. Effectiveness of gefitinib against non-small-cell lung cancer with the uncommon EGFR mutations G719X and L861Q. J Thorac Oncol. 2014;9:189-94.

24. Yang JC, Sequist LV, Geater SL, et al. Clinical activity of afatinib in patients with advanced non-small-cell lung cancer harbouring uncommon EGFR mutations: a combined post hoc analysis of LUX-Lung 2, LUX-Lung 3, and LUX-Lung 6. Lancet Oncol. 2015;16:830-8.

25. Miller VA, Hirsh V, Cadranel J, et al. Afatinib versus placebo for patients with advanced, metastatic non-small-cell lung cancer after failure of erlotinib, gefitinib, or both, and one or two lines of chemotherapy (LUX-Lung 1): a phase $2 b / 3$ randomised trial. Lancet Oncol. 2012;13:528-38.

26. Katakami N, Atagi S, Goto K, et al. LUX-Lung 4: a phase II trial of afatinib in patients with advanced non-small-cell lung cancer who progressed during prior treatment with erlotinib, gefitinib, or both. J Clin Oncol. 2013;31:3335-41.

27. Lee VH, Leung DK, Choy TS, et al. Efficacy and safety of afatinib in Chinese patients with EGFR-mutated metastatic non-small-cell lung cancer (NSCLC) previously responsive to first-generation tyrosine-kinase inhibitors (TKI) and chemotherapy: comparison with historical cohort using erlotinib. BMC Cancer. 2016;16:147.
28. Chang GC, Tseng CH, Hsu KH, et al. Predictive factors for EGFRtyrosine kinase inhibitor retreatment in patients with EGFRmutated non-small-cell lung cancer-a multicenter retrospective SEQUENCE study. Lung Cancer. 2017;104:58-64.

29. Schuler M, Yang JC, Park K, et al. Afatinib beyond progression in patients with non-small-cell lung cancer following chemotherapy, erlotinib/gefitinib and afatinib: phase III randomized LUX-Lung 5 trial. Ann Oncol. 2016;27:417-23.

30. Hanna N, Shepherd FA, Fossella FV, et al. Randomized phase III trial of pemetrexed versus docetaxel in patients with non-smallcell lung cancer previously treated with chemotherapy. J Clin Oncol. 2004;22:1589-97.

31. Garon EB, Ciuleanu TE, Arrieta O, et al. Ramucirumab plus docetaxel versus placebo plus docetaxel for second-line treatment of stage IV non-small-cell lung cancer after disease progression on platinum-based therapy (REVEL): a multicentre, double-blind, randomised phase 3 trial. Lancet. 2014;384:665-73.

Publisher's Note Springer Nature remains neutral with regard to jurisdictional claims in published maps and institutional affiliations.

\section{Affiliations}

\section{Hisashi Tanaka ${ }^{1}$ (1) Kageaki Taima $^{1} \cdot$ Masamichi Itoga ${ }^{1} \cdot$ Yoshiko Ishioka $^{1} \cdot$ Keisuke Baba $^{1} \cdot$ Toshihiro Shiratori $^{1}$. Hiroaki Sakamoto ${ }^{1}$. Junichiro Tsuchiya ${ }^{1} \cdot$ Hideyuki Nakagawa $^{2} \cdot$ Yukihiro Hasegawa $^{3} \cdot$ Hideo Yasugahira $^{4}$. Koichi Okudera ${ }^{5} \cdot$ Shingo Takanashi $^{6} \cdot$ Sadatomo Tasaka $^{1}$}

Kageaki Taima

taima0305@hotmail.com

Masamichi Itoga

gacchi88@hotmail.com

Yoshiko Ishioka

ishiokayoshiko@gmail.com

Keisuke Baba

babaeculus@gmail.com

Toshihiro Shiratori

sunday-song-hubris@ hirosaki-u.ac.jp

Hiroaki Sakamoto

sh1104235@gmail.com

Junichiro Tsuchiya

lichitbar-d@hirosaki-u.ac.jp

Hideyuki Nakagawa

nakahide@hirosaki-hosp.jp

Yukihiro Hasegawa

yukihiro_hasegawa@med.pref.aomori.jp

Hideo Yasugahira

hideo@htv-net.ne.jp
Koichi Okudera

hppokudera@gmail.com

Shingo Takanashi

t-shingo@hirosaki-u.ac.jp

Sadatomo Tasaka

tasaka@hirosaki-u.ac.jp

1 Department of Respiratory Medicine, Hirosaki University Graduate School of Medicine, 5, Zaifu-cho, Hirosaki, Aomori 036-8562, Japan

2 Department of Respiratory Medicine, Hirosaki National Hospital, Aomori, Japan

3 Department of Respiratory Medicine, Aomori Prefectural Central Hospital, Aomori, Japan

4 Department of Respiratory Medicine, Hachinohe City Hospital, Aomori, Japan

5 Department of Respiratory Medicine, Hirosaki Central Hospital, Aomori, Japan

6 Hirosaki University, Health Administration Center, Aomori, Japan 